\title{
Platelet Rich Plasma: Myth or Reality?
}

Platelet rich plasma (PRP), also termed autologous platelet gel, plasma rich in growth factors (PRGF), platelet concentrate (PC), is essentially an increased concentration of autologous platelets suspended in a small amount of plasma after centrifugation. Basically, patient's blood is collected and centrifuged at varying speeds until it separates into 3 layers: platelet poor plasma (PPP), PRP, and red blood cells. Usually 2 spins are used. The first spin ("Hard spin") separates the platelet poor plasma (PPP) from the red fraction and platelet rich plasma (PRP). The second spin ("Soft spin") separates the red fraction from the PRP. The material with the highest specific gravity (PRP) will be deposited at the bottom of the tube. Immediately prior to application, a platelet activator/agonist (topical bovine thrombin and $10 \%$ calcium chloridel is added to activate the clotting cascade, producing a platelet gel. The whole process takes approximately 12 minutes and produces a platelet concentration of 3-5x that of native plasma. ${ }^{1,2}$

Platelets play a fundamental role in hemostasis and are a natural source of growth factors. Growth factors, stored within platelet $\alpha$-granules, include platelet derived growth factor (PDGF), insulin like growth factor (IGF), vascular endothelial growth factor (VEGF), platelet derived angiogenic factor (PDAF), and transforming growth factor beta (TGF- $\beta$ ). The release of these growth factors is triggered by the activation of platelets that can be initiated by a variety of substances or stimuli such as thrombin, calcium chloride, or collagen. Growth factors are involved in key stages of wound healing and regenerative processes including chemotaxis, proliferation, differentiation, and angiogenesis. ${ }^{3}$ According to the definition of PRP, it may be assumed that these growth factors are present at increased concentrations in PRP. In addition to growth factors (GFs), platelets release numerous other substances le.g., fibronectin, vitronectin, sphingosine 1-phosphate, etc...) that are important in wound healing. An advantage of PRP over the use of single recombinant human growth factor delivery is the release of multiple growth factors and differentiation factors upon platelet activation. ${ }^{4}$ Recently, the morphologic and molecular configuration of PRP was reported, it showed PRP is a fibrin framework over platelets that has the potential to support regenerative matrix. .,6 $^{\text {. }}$

The rationale for using PRP in soft and hard augmentation are to accelerate vascularization of the graft, improve soft tissue healing, reduce post operative morbidity, and enhance bone regeneration. ${ }^{7}$ Advantages of using an autologous PRP include no risk of cross reactivity, immune reaction or disease transmission. ${ }^{8}$ In addition, the use of PRP improves handling of particulate graft materials and easier packing into a grafting site, thus facilitating space maintenance and potential bone regeneration. 9,10

Since PRP contains several GFs le.g., PDGF, VEGF, etc...) that are capable to stimulate angiogenesis and increase fibroblast cell differentiation, using PRP to promote soft tissue healing has been proposed. ${ }^{2}$ Research showed that PRP and analogous products improve graft adhesion and minimizes micro-movement, providing the most advantageous environment for graft acceptance. ${ }^{11,12}$ It has been also proposed that PRP accelerates wound maturity and epithelialization, hence decreased scar formation. PDGF and epidermal growth factor (EGF) are the main growth factors involved in fibroblast migration, proliferation, and collagen synthesis. Increased concentrations of these growth factors are likely the reason for the accelerated soft tissue wound healing, which is suggested to be at least 2-3 times faster than that of normal. ${ }^{13}$

For the hard tissue, growth factors released from PRP are likely to effect local vital cells such as osteoblasts. The addition of PRP to stromal cells has demonstrated angiogenic and osteogenic properties in animal models. ${ }^{14}$ The use of PRP to enhance bone regeneration has been documented in periodontal defects, ${ }^{15-17}$ extraction sockets, ${ }^{18}$ during implant placement, ${ }^{19,20}$ and in guided bone regeneration procedures around implants, including sinus augmentation. ${ }^{21}$

One of the major drawbacks of bone augmentation is the extended healing time required. Hence, one of the major reasons proposed for the use of PRP is a reduced healing time. A shortened graft healing time $(50 \%)$ has been demonstrated in sinus augmentation..$^{22}$ Accelerated bone regeneration has also been demonstrated in periodontal defects distal to second molars when PRP is added at the time of extraction of impacted third molars. ${ }^{18}$ Unfortunately these results cannot be used to expound the beneficial effects of PRP, as biopsies were not taken from any of the control sites.

In animal studies, when cancellous bone from the iliac crest was used as graft material for sinus lifts with or without PRP, biopsies showed both PRP and control groups achieved similar results with no statistically significant difference between the two. ${ }^{9.23}$ It is also true when DFDBA was used as a graft material, PRP did not enhance its ability to form bone. ${ }^{24}$ Similar findings were also reported when PRP was added to the xenograft (e.g., Bovine HA). ${ }^{25}$ These results are consistent with those above that failed to demonstrate enhanced bone regeneration when PRP is combined with non-living graft materials.

In humans, early controlled studies demonstrated 
enhanced healing and bone regeneration with PRP application. ${ }^{1.7}$ A short-term increase le.g., improved at 2 weeks but not at 12 weeks) of bone regeneration in sinus augmentation was observed when compared the $\beta$-TCP with or without PRP. ${ }^{26}$ Similar results have been demonstrated in minipigs, ${ }^{25}$ and adult domestic pigs. ${ }^{27}$

When FDBA was used with PRP for subantral sinus augmentation, results showed the application of PRP will only result in accelerated new bone formation if target cells such as osteoblasts and osteocytes are present. ${ }^{28} \mathrm{Also}$, study has reported that, when combined with anorganic bovine bone grafts, the addition of PRP had no effect on defect mineralization at any time point. ${ }^{26}$ This may be one of the reasons that several studies utilizing non vital grafting material have failed to show any beneficial effect. ${ }^{25,29,30}$

Numerous reports have been published regarding the favorable effects of PRP on wound healing after bone augmentation. However, many are case reports lacking controls. ${ }^{31-34}$ Hence, a standardized research protocol should be used for future studies. These include control of the quantification of platelet yield in both whole blood and PRP, use of commercial assays to quantify growth factor concentration, utilization of contralateral control groups, and proper histomorphometric analysis of specimens. The correlation between GF levels and histomorphometric result is another area that needs to be examined. One of theories behind why PRP does not work may be the concentration of PRP from the machine is too low for the GFs to show the clinical effect. It would be interested to know if the concentration is increased to 10 times (versus 3-4 times) over the plasma, what kind of clinical results illustrated.

Safety of PRP remains to be an issue since increases GF in a local area may be a cancer promoting effects. Other concern is the use of bovine thrombin in activating the PRP release to cause immunogenic reaction. ${ }^{35}$ So far most of published data showed it is safe to use the product, however, future study in this area is certainly needed.

Currently there is a paucity of critical scientific data regarding the beneficial effects of platelet rich plasma in clinical procedures. There have been animal and human studies both purporting and refuting its adjunctive positive effect. In theory, PRP has many beneficial effects such as autologous supply of growth factors and improved wound healing. In addition it is relatively inexpensive and readily available. However, from the current available literature it is clear that there is great variability in study design, clinical and radiographic parameters that were measured, and clinical outcome. Many studies claiming a positive beneficial effect suffer from a poor study design. Many have no controls or a limited sample size. In general, conclusions advocating for an adjunctive effect are not supported by the study design. Therefore, the use of this material cannot be supported at present, and further controlled, prospective clinical trials are urgently needed.

\section{ACKNOWLEDGEMENT}

This work was partially supported by the University of Michigan, Periodontal Graduate Student Research Fund.

\section{REFERENCES}

1. Marx RE, Carlson ER, Eichstaedt RM, Schimmele SR, Strauss JE, Georgeff KR. Platelet-rich plasma: Growth factor enhancement for bone grafts. Oral Surg Oral Med Oral Pathol Oral Radiol Endod 1998;85:638-646.

2. Petrungaro PS. Using platelet-rich plasma to accelerate soft tissue maturation in esthetic periodontal surgery. Compend Contin Educ Dent 2001;22:729-732, 734, 736 passim; quiz 746.

3. Bennett NT, Schultz GS. Growth factors and wound healing: biochemical properties of growth factors and their receptors. Am J Surg 1993;165:728-737.

4. Sanchez AR, Sheridan PJ, Kupp LI. Is platelet-rich plasma the perfect enhancement factor? A current review. Int $J$ Oral Maxillofac Implants 2003;18:93-103.

5. El-Sharkawy H, Kantarci A, Deady J, Hasturk H, Liu H, Alshahat $M$, et al. Platelet-rich plasma: growth factors and pro- and anti-inflammatory properties. J Periodontol 2007;78:661-669.

6. Fernandez-Barbero JE, Galindo-Moreno P, Avila-Ortiz G, Caba O, Sanchez-Fernandez E, Wang HL. Flow cytometric and morphological characterization of platelet-rich plasma gel. Clin Oral Implants Res 2006;17:687-693.

7. Anitua E. Plasma rich in growth factors: preliminary results of use in the preparation of future sites for implants. Int $J$ Oral Maxillofac Implants 1999;14:529-535.

8. Weibrich G, Kleis WK, Kunz-Kostomanolakis M, Loos $A H$, Wagner W. Correlation of platelet concentration in platelet-rich plasma to the extraction method, age, sex, and platelet count of the donor. Int J Oral Maxillofac Implants 2001;16:693-699.

9. Jakse N, Tangl S, Gilli R, Berghold A, Lorenzoni M, Eskici $A$, et al. Influence of PRP on autogenous sinus grafts. An experimental study on sheep. Clin Oral Implants Res 2003; 14:578-583.

10. Freymiller EG, Aghaloo TL. Platelet-rich plasma: ready or not? J Oral Maxillofac Surg 2004;62:484-488.

11. Whitman DH, Berry RL, Green DM. Platelet gel: an autologous alternative to fibrin glue with applications in oral and maxillofacial surgery. J Oral Maxillofac Surg 1997;55:1294-1299.

12. Carlson NE, Roach RB, Jr. Platelet-rich plasma: clinical applications in dentistry. $J$ Am Dent Assoc (1939) 2002;133:1383-1386.

13. Anitua E, Andia I, Ardanza B, Nurden P, Nurden AT. 
Autologous platelets as a source of proteins for healing and tissue regeneration. Thromb Haemost 2004;91:4-15.

14. Lucarelli E, Donati D, Cenacchi A, Fornasari PM. Bone reconstruction of large defects using bone marrow derived autologous stem cells. Transfus Apher Sci 2004;30:169-174.

15. Hanna R, Trejo PM, Weltman RL. Treatment of intrabony defects with bovine-derived xenograft alone and in combination with platelet-rich plasma: a randomized clinical trial. J Periodontol 2004;75:1668-1677.

16. Okuda K, Tai H, Tanabe K, Suzuki H, Sato T, Kawase $T$, et al. Platelet-rich plasma combined with a porous hydroxyapatite graft for the treatment of intrabony periodontal defects in humans: a comparative controlled clinical study. J Periodontol 2005;76:890-898.

17. Lekovic V, Camargo PM, Weinlaender M, Vasilic N, Kenney EB. Comparison of platelet-rich plasma, bovine porous bone mineral, and guided tissue regeneration versus platelet-rich plasma and bovine porous bone mineral in the treatment of intrabony defects: a reentry study. $J$ Periodontol 2002;73:198-205.

18. Sammartino G, Tia M, Marenzi G, di Lauro AE, D'Agostino E, Claudio PP. Use of autologous platelet-rich plasma (PRP) in periodontal defect treatment after extraction of impacted mandibular third molars. J Oral Maxillofac Surg 2005;63:766-770.

19. Monov G, Fuerst G, Tepper G, Watzak G, Zechner W, Watzek $G$. The effect of platelet-rich plasma upon implant stability measured by resonance frequency analysis in the lower anterior mandibles. Clin Oral Implants Res 2005;16:461465.

20. Kim SG, Kim WK, Park JC, Kim HJ. A comparative study of osseointegration of Avana implants in a demineralized freeze-dried bone alone or with platelet-rich plasma. $J$ Oral Maxillofac Surg 2002;60:1018-1025.

21. Kim SG, Chung CH, Kim YK, Park JC, Lim SC. Use of particulate dentin-plaster of Paris combination with/ without platelet-rich plasma in the treatment of bone defects around implants. Int $J$ Oral Maxillofac Implants 2002;17:86-94.

22. Kassolis JD, Reynolds MA. Evaluation of the adjunctive benefits of platelet-rich plasma in subantral sinus augmentation. J Craniofac Surg 2005;16:280-287.

23. Butterfield KJ, Bennett J, Gronowicz G, Adams D. Effect of platelet-rich plasma with autogenous bone graft for maxillary sinus augmentation in a rabbit model. $J$ Oral Maxillofac Surg 2005;63:370-376.

24. Grageda E, Lozada JL, Boyne PJ, Caplanis N, McMillan PJ. Bone formation in the maxillary sinus by using platelet-rich plasma: an experimental study in sheep. $J$ Oral Implantol 2005;31:2-17.
25. Furst G, Gruber R, Tangl S, Zechner W, Haas R, Mailath G, et al. Sinus grafting with autogenous platelet-rich plasma and bovine hydroxyapatite. A histomorphometric study in minipigs. Clin Oral Implants Res 2003;14:500-508.

26. Wiltfang J, Schlegel KA, Schultze-Mosgau S, Nkenke E, Zimmermann R, Kessler P. Sinus floor augmentation with beta-tricalciumphosphate (beta-TCP): does platelet-rich plasma promote its osseous integration and degradation? Clin Oral Implants Res 2003;14:213-218.

27. Thorwarth M, Wehrhan F, Schultze-Mosgau S, Wiltfang $J$, Schlegel KA. PRP modulates expression of bone matrix proteins in vivo without long-term effects on bone formation. Bone 2006;38:30-40.

28. Kassolis JD, Rosen PS, Reynolds MA. Alveolar ridge and sinus augmentation utilizing platelet-rich plasma in combination with freeze-dried bone allograft: case series. J Periodontol 2000;71:1654-1661.

29. Froum SJ, Wallace SS, Tarnow DP, Cho SC. Effect of platelet-rich plasma on bone growth and osseointegration in human maxillary sinus grafts: three bilateral case reports. Int J Periodontics Restorative Dent 2002;22:45-53.

30. Wiltfang J, Kloss FR, Kessler P, Nkenke E, SchultzeMosgau S, Zimmermann R, et al. Effects of platelet-rich plasma on bone healing in combination with autogenous bone and bone substitutes in critical-size defects. An animal experiment. Clin Oral Implants Res 2004;15:187193.

31. Philippart P, Daubie V, Pochet R. Sinus grafting using recombinant human tissue factor, platelet-rich plasma gel, autologous bone, and anorganic bovine bone mineral xenograft: histologic analysis and case reports. Int $J$ Oral Maxillofac Implants 2005;20:274-281.

32. Mazor Z, Peleg M, Garg AK, Luboshitz J. Platelet-rich plasma for bone graft enhancement in sinus floor augmentation with simultaneous implant placement: patient series study. Implant Dent 2004;13:65-72.

33. Rosenberg ES, Torosian J. Sinus grafting using plateletrich plasma--initial case presentation. Pract Proced Aesthet Dent 2000;12:843-850; quiz 852.

34. Thor A, Wannfors K, Sennerby L, Rasmusson L. Reconstruction of the severely resorbed maxilla with autogenous bone, platelet-rich plasma, and implants: 1year results of a controlled prospective 5-year study. Clin Implant Dent Relat Res 2005;7:209-220.

35. Landesberg R, Moses M, Karpatkin M. Risks of using platelet rich plasma gel. J Oral Maxillofac Surg 1998;56:1116-1117. 